\title{
Anticipating the long-term cardiovascular effects of COVID-19
}

\author{
Richard C. Becker ${ }^{1}$ \\ Published online: 3 September 2020 \\ (c) Springer Science+Business Media, LLC, part of Springer Nature 2020
}

\section{Introduction}

SARS-CoV2 infection can impact all organs structurally and functionally. Persisting symptoms in patients recovering from coronavirus disease 2019 (COVID-19) are common and with close follow-up can be detected in nearly $90 \%$ of patients 60 days from the original diagnosis [1]. The most common symptoms are fatigue, dyspnea, joint pain, chest pain, cough, insomnia and headache. Given the well-documented involvement of the circulatory system in COVID-19, including small, moderate and large-sized veins and arteries, coupled with robust immune and resulting local and systemic inflammatory responses, one would anticipate a prolonged recovery period and potentially longterm cardiovascular effects. The following editorial review summarizes the pathogenesis of structural, functional and metabolic abnormalities associated with COVID-19 and postulates long-term cardiovascular effects and management strategies under a broad clinical umbrella referred to as postCOVID-19 syndrome.

\section{Acute stages of COVID-19: setting the stage for prolonged clinical effects}

The frequency of cardiac injury, vascular dysfunction and thrombosis in patients with COVID-19, including those persons with either no or minimal symptoms during their initial infection, raises important questions about potential longterm cardiovascular effects: these could include heart failure, life-threatening arrhythmias, sudden cardiac death, impaired myocardial flow reserve from microvascular injury, coronary artery and aorta aneurysm formation, hypertension, labile

Richard C. Becker

Richard.becker@uc.edu

1 Department of Medicine, University of Cincinnati Heart and Circulation Research Institute, University of Cincinnati College of Medicine, 231 Albert Sabin Way, Cincinnati, OH 45267, USA heart rate and blood pressure responses to activity, accelerated atherosclerosis and both venous and arterial thromboembolic disease [2]. Indeed, events during the acute phase of disease, including those that are clinically unsuspected and undiagnosed [3] will increase the risk for recurring events [4-6]. How will the medical community follow patients with COVID-19? How will future events be prevented?

The COVID-19 pandemic and its reporting has focused primarily on two areas - the number of cases and the number of deaths. Both statistics are of great importance, yet neither sufficiently captures an equally important metric of morbidity that is responsible for resource utilization, assessment of vulnerable populations, cost, recovery, long-term health effects, and quality of life [7]. A morbidity index of COVID-19 survivors is particularly relevant when considering co-morbid factors and traits for SARS-CoV-2 infection susceptibility, need for hospitalization, level of care and their collective impact on the severity of illness [8]. Indeed, selfreported data from the 2018 Behavioral Risk Factor Surveillance System and the United States Census population data identified medical conditions in $47.2 \%$ of adults living in countries throughout the United States. While the number of persons with co-morbid conditions was highest in population-dense metropolitan areas, the overall prevalence was highest in rural areas [9] (Fig. 1). Translated to healthcare access and preparedness, the medical community, including health systems must work closely with city, county and state leaders and planners, the private sector, epidemiologists and health commissioners to address the needs of two specific patient populations-those with worsened states of chronic illness and those with new, residual and potentially prolonged conditions spanning a wide range following COVID-19.

\section{Acute cardiac injury}

Myocardial Infarction stemming from supply-demand mismatch (Type 2) is common in clinical practice and considered to be ischemic in etiology [10]. Patients with COVD-19 can experience hypoxia, hypotension and distributive shock 
Fig. 1 Map showing modelbased estimates of United States prevalence $\mathbf{a}$ and number b of adults aged $\geq 18$ years with any selected underlying medical condition, by county, in the United States, in 2018.

* Selected underlying conditions include chronic obstructive pulmonary disease, emphysema, or chronic bronchitis; heart disease (angina or coronary heart disease, heart attack, or myocardial infarction); diabetes; chronic kidney disease; or obesity (body mass index $\geq 30 \mathrm{~kg} /$ $\mathrm{m}^{2}$ ). Adopted with permission from Ebinger [54]

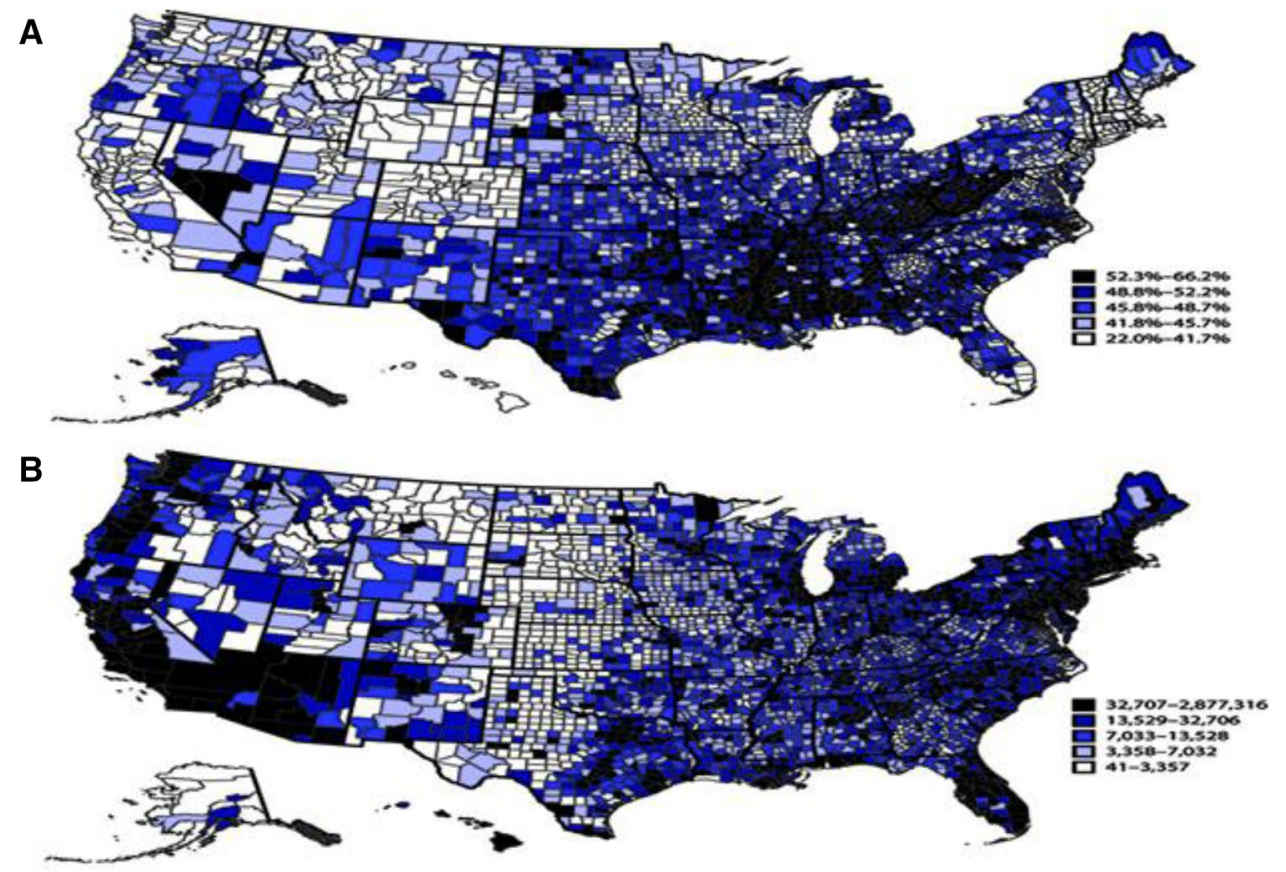

with resulting myocardial injury diagnosed by serial cardiac troponin assays with quantitative values $>99$ th percentile of the upper reference limit determined in a normal reference population [2]. In addition, COVID-19-associated coagulopathy and hyperinflammation syndrome can cause micro and macro-myocardial injury of non-ischemic etiology [11].

Type 2 myocardial infarction is associated with one-year mortality rates of 10-25\% [10] owing to co-morbid conditions and underlying atherosclerotic cardiovascular disease. Similar mortality rates have been reported following nonischemic myocardial injury. In COVID-19, small vessel inflammation, injury and dysfunction contribute to myocyte damage, as does pericyte injury and impaired myocardial perfusion [11].

Early reports of COVID-19 identified a high proportion of hospitalized patients with reduced left ventricular ejection fraction. Indeed, in one series $35 \%$ of patients had an ejection fraction less than $50 \%$ and features of stress-induced cardiomyopathy were identified in a number of patients [12]. Patients with COVID-19-associated myocardial injury likely remain at risk for cardiovascular events following hospital discharge (Fig. 2). The duration of risk, optimal surveillance and management strategies are under investigation and must be clearly defined.

\section{Viral myocarditis}

\section{Fundamental constructs}

Myocarditis occurs in a wide range of acute viral infections, including adenovirus, Human Immunodeficiency

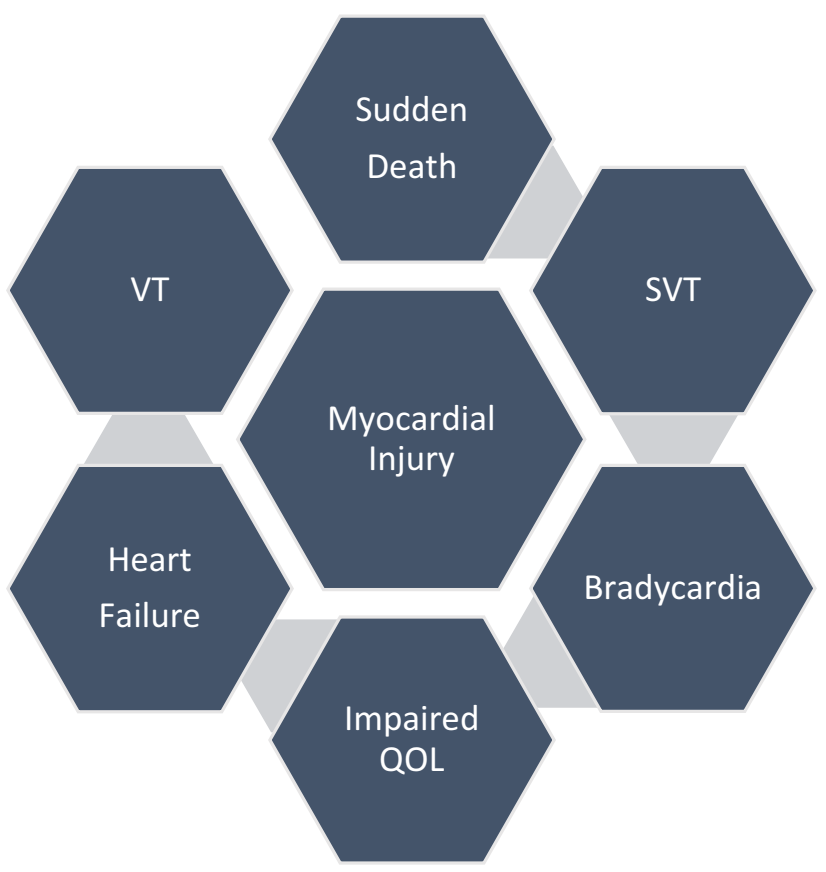

Fig. 2 COVID-19 is associated with ischemic and non-ischemic myocardial injury that can be clinical or subclinical in the acute, subacute and chronic phases of SARS-CoV-2 infection. The risk for clinical events following initial recovery is under investigation, but monitoring and follow-up assessment should be integrated into the continuum of care to minimize the likelihood of life-threatening and life-altering events. $V T$ ventricular tachycardia, $S V T$ supraventricular tachycardia, $Q O L$ quality of life

Virus (HIV), Epstein-Barr Virus, and Influenza virus to name a few. Observational data, coupled with virologic and 
molecular diagnostic studies suggest that enteroviruses, including coxsackievirus, parvovirus and adenovirus are among the most common causes of myocarditis.

Animal models of enterovirus-induced myocarditis demonstrate RNA detection in the acute phase and chronic phase of dilated cardiomyopathy. In a murine model of coxsackievirus $\beta 3$-myocarditis, features of acute infection including rapid progression of myocardial lesions, infected myocytes and inflammatory cells is followed by a persistent pattern with reduced inflammation and a slow progression of myocardial lesions. Infection is often restricted to atrophic myocytes and fibroblasts [13].

While the virus itself is cytoxic causing myocyte injury, a majority of cases of severe myocarditis and subsequent post-viral cardiomyopathy are governed by a maladaptive or overly robust inflammatory response to viral antigens [14] (Fig. 3). Many viruses associated with myocarditis infect the heart secondarily following an initial infection in the lungs or gastrointestinal tract. By contrast, some viruses are highly cardiotropic. For example, parvovirus $\beta 19$ can infect the endothelial cells of venules, capillaries and arterioles [15]. Cytokine activation follows, causing apoptosis of endothelial cells, endothelial dysfunction and marked lymphocyte accumulation within the microvasculature. Myocyte injury is the result of perfusion abnormalities rather than direct myocyte viral entry and damage.

Myocarditis following a viral infection is viewed under the pathophysiology-based lens of autoinflammatory disease [16]. The inflammatory process can include the myocytes, interstitial elements or vasculature of the heart. $\mathrm{T}$ helper

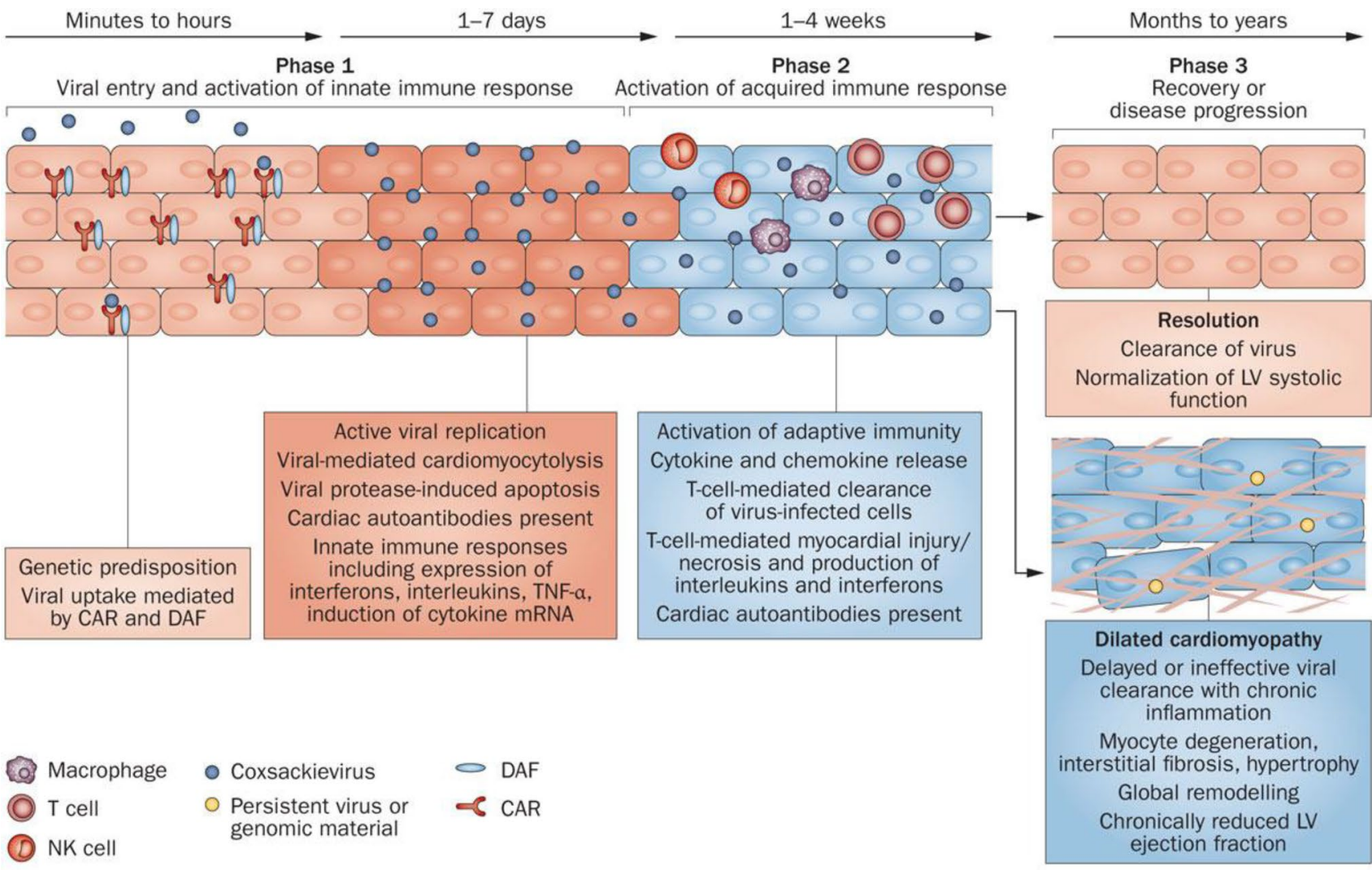

Nature Reviews | Cardiology

Fig. 3 Phases of viral-associated cardiomyopathy: phase 1 commences with viral entry into the host and transit to the myocardium. In predisposed individuals, coxsackievirus binds to DAF on the cell surface, which shuttles the virus towards the CAR, localized at cell-cell junctions. The complex is internalized by the cell, triggering numerous cellular responses and activation of host innate immunity. Virus replication within the cardiomyocyte causes cell lysis, which prompts a set of cascades leading to the release of cytokines. In phase 2, both cellular and humoral responses contribute to autoimmune-mediated injury. The first immune cells recruited to the injured myocardium are NK cells, followed by macrophages. Infiltration of $\mathrm{T}$ cells typically peaks at 7-14 days; this timing coincides with the most severe phase of disease. As viral titer decrease, inflammation subsides (phase 3) and some individuals experience complete resolution of myocardial injury. However, in other patients, viral genomic material persists (in some cases up to 12 months; viral persistence throughout the entirety of end-stage disease until time of transplantation has been demonstrated), contributing to chronic inflammation and dilated cardiomyopathy. Abbreviations $C A R$ coxsackievirus and adenovirus receptor, $D A F$ decay accelerating factor, $L V$ left ventricular, $N K$ natural killer, $T N F$ tumour necrosis factor. Adopted with permission from Pollack [14] 
cells are produced in response to antigen presenting cells followed by the release of cytokines - a primary mediator of tissue injury. In response to myocyte and surrounding interstitial and vascular damage, the release of self-antigens can cause an injurious autoimmune response-a process referred to as molecular mimicry or bystander activation [17].

\section{SARS-CoV-2-associated myocarditis}

Given the duration of viral shedding in SARS-CoV-2 infection and COVID-19, as well as the relatively high density of ACE2 receptors expressed in cardiomyocytes, one might anticipate cases of myocarditis and myopericarditis [2]. Lindner and colleagues performed autopsies on 39 decedents (median age 85 years) with COVID-19. Cardiac tissue contained SARS-CoV-2 in 24 decedents (61.5\%). Viral loads above 1000 copies per $\mu$ q RNA were documented in 16 cases (41.0\%). Proinflammatory gene upregulation was present in each decedent with high viral loads [18]. A prospective observational cohort study of 100 adult patients with severe COVID-19 and subsequent recovery compared to age- and sex-matched healthy volunteers and risk factor-matched patients was conducted by Puntmann and colleagues [19]. The median time from diagnosis and cardiac MRI was 71 (64-92) days. At the time of cMRI high sensitivity (hs) troponin was detectable in $75 \%$ of patients, NT pro-BNP (brain naturetic polypeptide) was normal. Compared with the control groups, patients recovered from COVID-19 had lower left ventricular ejection fraction, higher left ventricular volumes, higher left ventricular mass and raised $\mathrm{T} 1$ and $\mathrm{T} 2$ weighted images. Overall, 78 of 100 patients had abnormal cMRIs with raised myocardial native T1, raised myocardial native T2, myocardial late gadolinium enhancement and/ or pericardial enhancement. Endomyocardial biopsies were performed in patients with the most abnormal cMRI findings and revealed lymphocytic inflammation. The overall finding suggests that $\sim 80 \%$ of patients with severe COVID-19 have cardiac involvement and nearly $25 \%$ have evidence of ongoing myocardial inflammation three months after diagnosis. Intuitively, these are among the patients who require followup and clear management strategies given their inherent risk for poor outcomes.

\section{Natural history and clinical events}

The natural history of viral myocarditis varies considerably, ranging from minimal symptoms to fulminant heart failure, cardiogenic shock, ventricular arrhythmias, post-viral cardiomyopathy and complete resolution without residual structural or functional abnormalities. Patients with preserved left ventricular function at the time of diagnosis tend to have a good long-term prognosis. For those with a moderate-to-severely reduced left ventricular ejection fraction, approximately half will have recovery over the next 6-12 months, 25\% will experience chronic systolic dysfunction and $25 \%$ will worsen and require advanced mechanical therapies or heart transplantation [20].

The long-term effects of SARS-CoV-2-associated myocarditis are not known, but as summarized above for viral myocarditis could include heart failure, impaired exercise tolerance, atrial tachyarrhythmias, ventricular tachyarrhythmias, bradyarrhythmias and sudden cardiac death. Subclinical myocarditis may portend a particularly high risk for sudden death during moderate-to-high intensity physical activity, raising concern and a cautionary note in the athletic community $[21,22]$.

\section{Acute kidney injury}

The widely disseminated organ involvement among patients with COVID-19 is recognized. While any organ can be impacted, this section will focus on kidney pathology and its functional interface with the cardiovascular system. Su and colleagues reviewed the histopathology of 26 decedents with COVID-19 [23]. There were findings of acute tubular injury in all persons. Collapsing variants of focal sequential glomerulosclerosis has also been reported [24]. Among hospitalized patients with COVID-19, an incidence rate of acute kidney injury (AKI) has approached 50\% [25].

AKI has been associated with long-term cardiovascular events [26]. A process referred to as reno-cardiac syndrome (Type 3 cardio-renal syndrome). While the responsible mechanism(s) are not known, remote cardiac injury, dysfunction and fibrosis could be mediated, at least in part, by galectin-3 overexpression [27]. The long-term effects of COVID-19-associated AKI have not been defined; however, the high incidence of comorbid factors among patients with severe disease suggests that pre-existing kidney disease will be common. Further, established kidney disease is a risk factor for poor recovery, relapsing AKI and non-reversibility following an acute insult [28].

The mechanisms responsible for reno-cardiac syndrome have been investigated, and include the following: cellular injury-associated chemokine and cytokine secretion with myocardial inflammation, injury, apoptosis and necrosis [28]. The most cytotoxic cytokines are interferon- $\gamma$, tumor necrosis factor and interleukin (IL) $1 \beta$. The inflammatory response also facilitates leukocyte infiltration into the myocardium [29]. Activation of the sympathetic nervous system and renin-angiotensin-aldosterone system also contribute to myocardial injury as do changes in blood $\mathrm{pH}$ and electrolyte abnormalities [30] (Fig. 4).

The long-term cardiovascular events following AKI have been summarized [31]. In addition to higher adjusted rates of chronic kidney disease and its progression, AKI was associated with heart failure and al-cause death, particularly in 


\section{Cardio-Renal Syndrome (Type 3)}

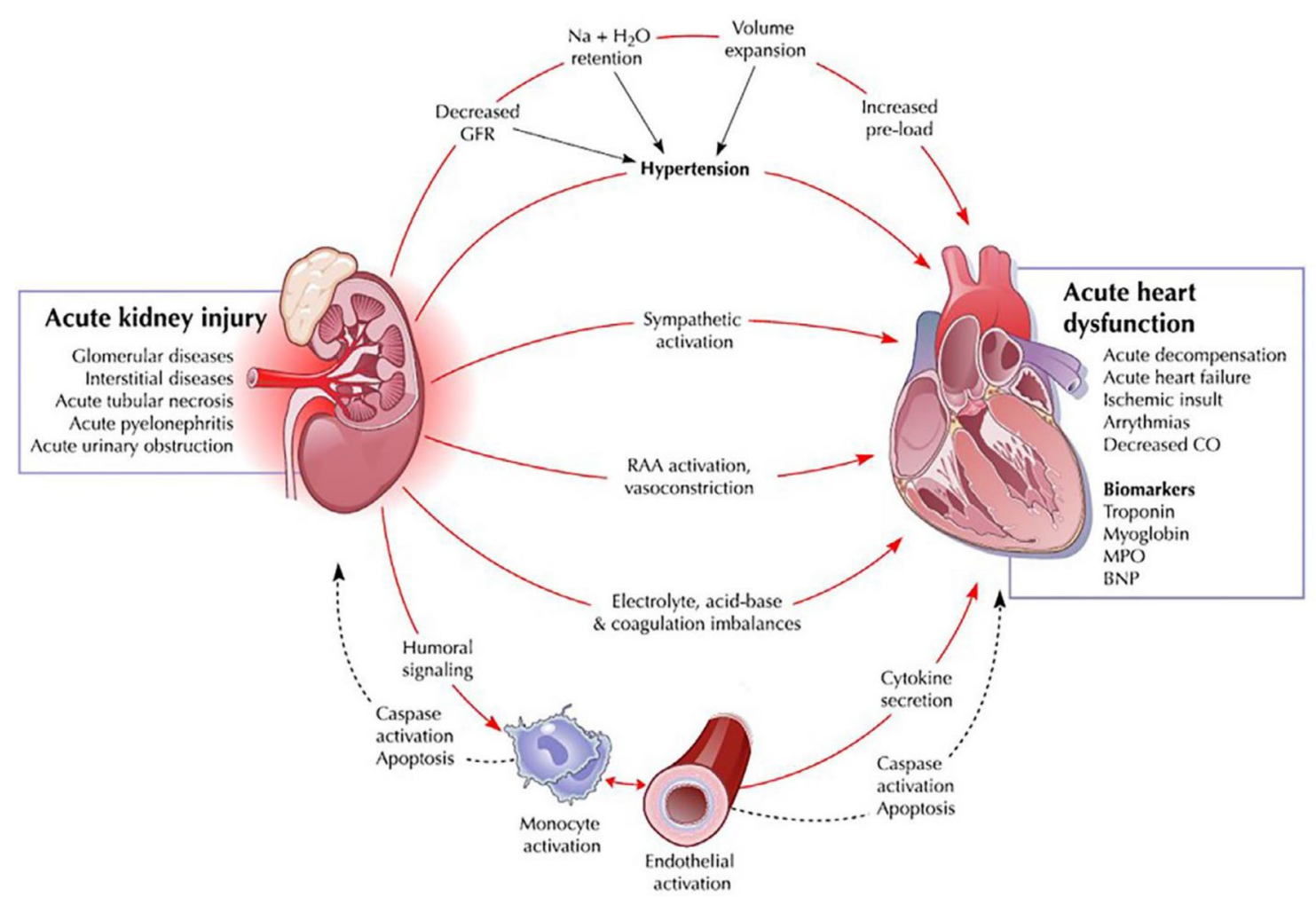

Fig. 4 Pathophysiologic pathways in Type 3 cardiorenal syndrome. Acute Kidney Injury (AKI) is the initial insult in Type 3 CRS and can result from many potential etiologies. AKI is thought to have both direct and indirect effects on cardiac structure and function leading to acute cardiac injury. Direct mechanisms include RAA and SNS activation. Indirect mechanisms include volume overload, electrolyte

patients without signs of renal recovery by 3 months following the acute event.

\section{Acute vascular injury}

The vascular pathology of COVID-19 is a topic of great interest [11]. As previously described, necropsy and postmortem biopsies of decedents with COVID-19 have consistently shown endotheliitis and accompanying macro and microvascular thrombosis within arteries, veins, arterioles, capillaries and venules in all major organs [32, 33]. Endothelial cells produce microvesicles in response to inflammatory conditions and inflammatory mediators, including cytokines, thrombin and complement 5a [34]. In turn, microvesicles impair vascular integrity, gap junctions, promote neutrophil binding, release NETs and facilitate tissue-level inflammation.

The wide-spread vasculitis described in patients with COVID-19 likely contributes to thrombosis, hemodynamic disturbances, and acidemia. Acute cardiac injury can take multiple forms including acute heart failure, cardiac ischemia, and arrhythmia. Abbreviations $B N P$ brain natriuretic peptide, GFR glomerular filtration rate, $M P O$ myeloperoxidase, $R A A$ renin-angiotensin-aldosterone, $C R S$ cardiorenal syndrome. Adopted with permission from Ronco [30]

instability and autonomic dysregulation. The question being raised is, "how long will the vascular injury persist and at what cost to a full and functional recovery"?

\section{Baroreceptor dysfunction}

The diffuse endotheliitis and vascular injury observed among patients with COVID-19 may have lasting hemodynamic and autonomic regulatory effects. The arterial baroreceptor system is intimately involved on a momentto-moment basis with maintaining vascular tone and blood pressure homeostasis [35]. For example, arterial baroreceptors (stretch receptors located in the carotid sinuses and aortic arch) provide continuous feedback on blood pressure to the central nervous system, which responds with physiological efferent autonomic activity. Activation of arterial baroreceptors in response to increased blood pressure causes activation of vagal cardio-inhibitory neurons and a decrease of sympathetic neuron discharges to the heart and peripheral 
resistance bed [36]. The end-result is a decrease in heart rate, cardiac contractility, peripheral vascular resistance and venous return. By contrast, a decrease in sympathetic activity and vagal inhibition, leads to tachycardia and heightened cardiac contractility, vascular resistance and venous return. Any changes to this finely tuned mechanism can cause impaired blood pressure and heart rate responses to a change in posture, sleep and other resting states and physical activity. COVID-19-associated dysautonomia could be one of several manifestations of diffuse vascular injury [37].

\section{Molecular and cellular adaptation, maladaptation and reset states: potential role in recovery following COVID-19}

The early stages of COVID-19 are driven by a rapidly replicating virus and its direct effects on host cells. The transition stage of disease is less about the virus itself and more aligned with host responses, particularly unregulated immune and inflammatory system activation. SARS-CoV-2 tolerance is an attractive construct because its primary goals are to limit maladaptive response, attenuate tissue/organ damage, preserve physiological function and initiate recovery [38]. By contrast, these same mechanisms if poorly regulated either because of comorbid illness or the virus itself may contribute to long-term pathological effects.

\section{Immune mechanisms}

The variability of symptoms experienced by persons with COVID-19 is one of many areas of investigation. Braun et al. [39] investigated SARS-CoV-2 spike protein reactive $\mathrm{CD}^{+}{ }^{+} \mathrm{T}$ cells in patients with COVID-19 and SARS-CoV-2 unexposed healthy donors. Peripheral blood SARS-CoV-2 S-reactive $\mathrm{CD}^{+}{ }^{+} \mathrm{T}$ cells were detected in $83 \%$ and $35 \%$ of samples, respectively. Among healthy donors the S-reactive $\mathrm{CD} 4^{+} \mathrm{T}$ cells reacted primarily to $\mathrm{C}$-terminal $\mathrm{S}$ epitopes that displayed homology to spike glycoproteins of human endemic coronaviruses. S-reactive T cell lines cross-reacted to SARS-CoV-2 C-terminal S protein epitopes. The impact of S-cross-reactive $\mathrm{T}$ cells on vaccine response will be an important area of investigation.

SARS-CoV-2 disrupts normal immune responses, leading to both an impaired immune system and, in some cases, an uncontrolled inflammatory response [40]. Under ideal conditions, treatment(s) would be designed to enhance viral immunity and attenuate systemic inflammation. Immune patterns are associated with disease progression and severity in patients with COVID-19. The patterns described to date are as follows: lymphopenia, reduced $\mathrm{CD} 4^{+} \mathrm{T}, \mathrm{CD} 8^{+}$ $\mathrm{T}$, memory helper $\mathrm{T}$ cells, natural killer cells and $\mathrm{B}$ cells, $\mathrm{T}$ cell activation with expression of CD69, CD38, CD44,
OX40, IL-2, TNF- $\alpha$, and IFN- $\gamma$, T-cell and natural killer T cell exhaustion, decreased basophils, eosinophils and monocytes, increased production of cytokines (IL-1 $\beta$, IL-1RA, IL-2, IL-6, IL-7, IL-8, IL-9, IL-10, IL-17, TNF- $\alpha$, IFN- $\gamma$, G-CSF, IP10, McP1 and MIP1 $\alpha$ ) and increased IgG and total antibodies.

Wen et al. [41] characterized transcriptional changes in peripheral blood mononuclear cells in the recovery phase of COVID-19. Monocytes increased and lymphocytes decreased during recovery. Specifically, $\mathrm{CD} 14^{+}$monocytes with high inflammatory gene expression patterns increased, and while $\mathrm{CD} 4^{+} \mathrm{T}$ cells and $\mathrm{CD} 8^{+} \mathrm{T}$ cells decreased, they too displayed high levels of pro-inflammatory genes. An integration analysis predicted that IL-1 $\beta$ and M-CSF may represent novel gene targets to prevent or attenuate a cytokine storm state. Similarly, the analysis suggested that TNFSF13, IL-18, IL-2 and IL-4 may be beneficial during the recovery phase.

Patients experiencing moderate or severe COVID-19 have pulmonary epithelial cells with a three-fold increased expression of ACE2 receptors compared to healthy controls [42]. The expression pattern correlates with interferon signals by immune cells. Compared to patients with moderate acuity, critically ill patients' exhibit heightened interactions between epithelial cells and immune cells as evidenced by the following: ligand-receptor expression profiles and inflammatory macrophage expression of CCL-2, CCL-3, CXCL-1, CXCL-10, IL-8, IL-1 $\beta$ and TNF genes.

\section{Metabolic mechanisms}

A comprehensive and scholarly overview of COVID-19 from a metabolic perspective lays the foundation for infection proclivity, clinical spectrum, recovery and the potential [43] long-term metabolic consequences (Fig. 5).

Metabolic health is likely important for SARS-CoV-2 infection susceptibility, the severity of COVID-19-associated organ damage and their recovery. Several supporting examples have emerged during the pandemic, including age, obesity, diabetes mellitus and hypertension. Each is associated with impaired immune function, metabolic derangements and a heightened baseline state of systemic inflammation (Fig. 6) [38, 44]. In addition, each condition causes vascular injury, predisposes to atherosclerotic plaque development and is associated with chronic kidney disease-a recognized and potent risk factor for atherosclerotic cardiovascular disease [45-47].

The association between viral infections and long-term metabolic abnormalities is recognized. Wang summarized the recovery pathway among patients with severe acute respiratory syndrome (SARS) - a global epidemic that emerged in 2003 [48]. Lung performance did not return to normal for 6-12 months following. Six min walk distance improved in the first 6 months of recovery, however, it did 


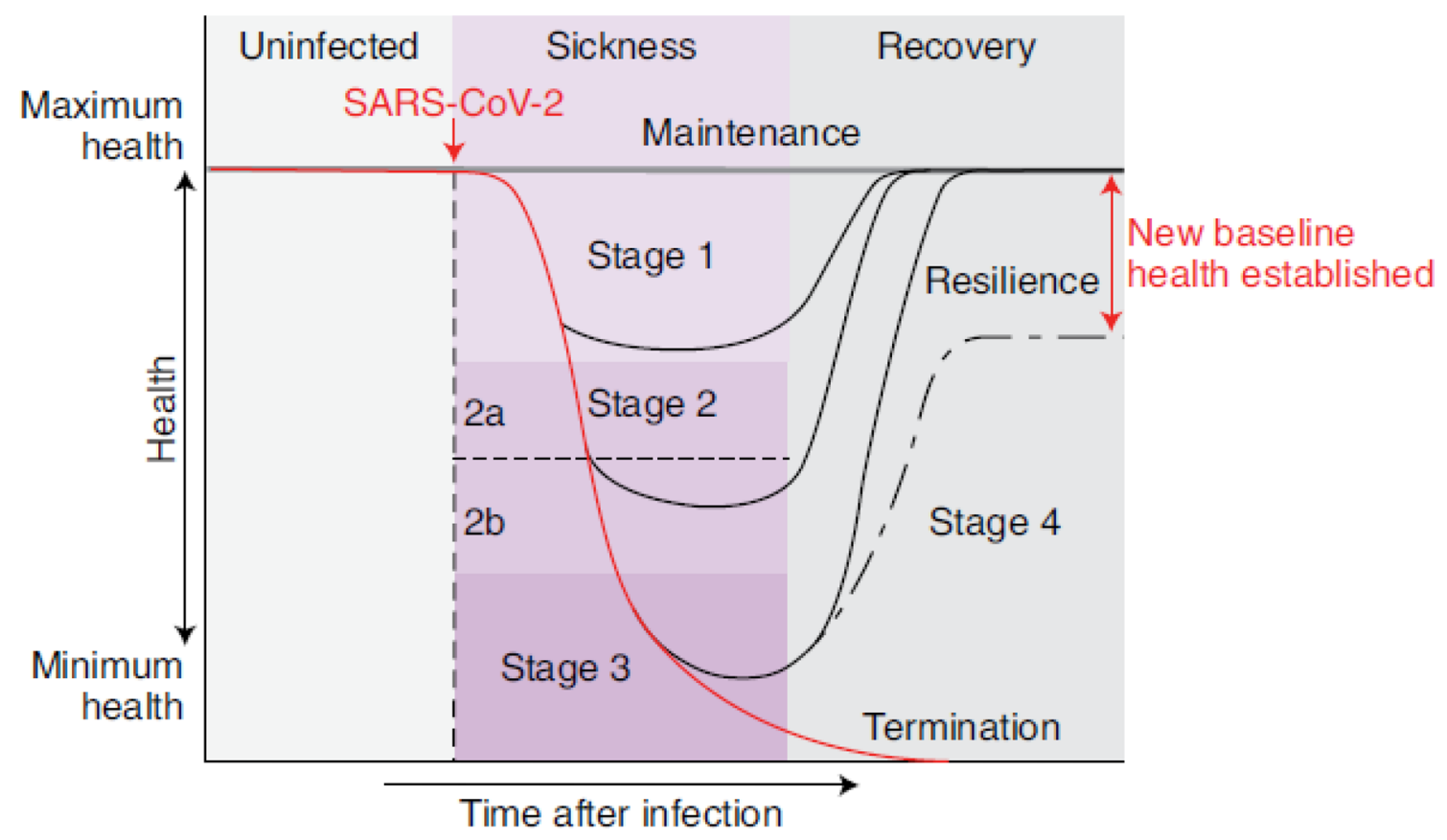

Fig. 5 The disease phases of patients with COVID-19. After infection, patients can remain healthy and show no signs of sickness (maintenance of health). For patients who develop symptoms, the disease course can be described by four stages. Stage 1 is mild, and patients exhibit fever, malaise and a dry cough. Stage 2 is characterized by a pneumonia phase without or with hypoxia $(2 a, b)$. Patients who progress further along the disease course develop acute res-

not reach normal values and physical activity-related quality of life scores were much lower than normal populations even at 1-year. The findings suggest that muscle weakness can persist for a prolonged period after a severe respiratory infection. As with other serious illnesses, neurocognitive impairment (memory, recall, attention and concentration) and physiologic effects (depression, post-traumatic stress) can persist for months to years.

Wu et al. [49] recruited 25 patients greater than 10 years following recovery from SARS. They identified a lingering susceptibility to lung infections, abnormal glucose metabolism and increased phosphatidylinositol levels compared to healthy controls.

Sasannejah and colleagues [50] summarized the wide range of long-term neurocognitive impaired states that follow severe respiratory infections complicated by acute respiratory distress syndrome (ARDS). While pre-existing conditions contributed, in many instances the acute respiratory illness accompanied by sympathetic activation, altered cerebral microvascular integrity, changes in intracranial pressure, systemic inflammation-associated blood-brain barrier dysfunction and cytokine-mediated hippocampal damage was believed to be primarily responsible. piratory distress syndrome, shock or multiorgan failure (stage 3 III). Patients who recover (stage 4) from the infection show a resilience phenotype. Some patients may never return to their original health state, thus establishing a new baseline for health. Patients who peak in stages 1 or 2 will bypass stage 2 or 3 , respectively, and enter into their recovery phase. Adopted with permission from Ayres [43]

\section{Lipid mechanisms}

The risk for COVID-19 on a high-spectrum of severity is heightened by metabolic and lipid-related comorbid factors. Because lipids play an important role in regulation of immunity, changes in lipidomic profiles could have both near-term and long-term consequences. Song et al. [51] performed lipodomic and metabolomic profiling in patients with COVID-19. They identified increased monosialodihexosyl, ganglioside-enriched exosomes and decreased diacylglycerols. The immediate effects may apply most to virus binding and to host cell entry, however, there may be longer-term effects on cellular signaling, glucose homeostasis, membrane integrity and ion regulation.

\section{Vascular mechanisms}

Ackerman and colleagues performed a detailed necropsy-based analysis of COVID-19 decedents [52]. In all cases there was diffuse alveolar damage with necrosis of alveolar lining cells, Type 2 pneumatocyte hyperplasia and linear intra-alveolar fibrin deposition. A multiplexed analysis identified 79 inflammation-related genes that were differentially expressed compared to influenza 


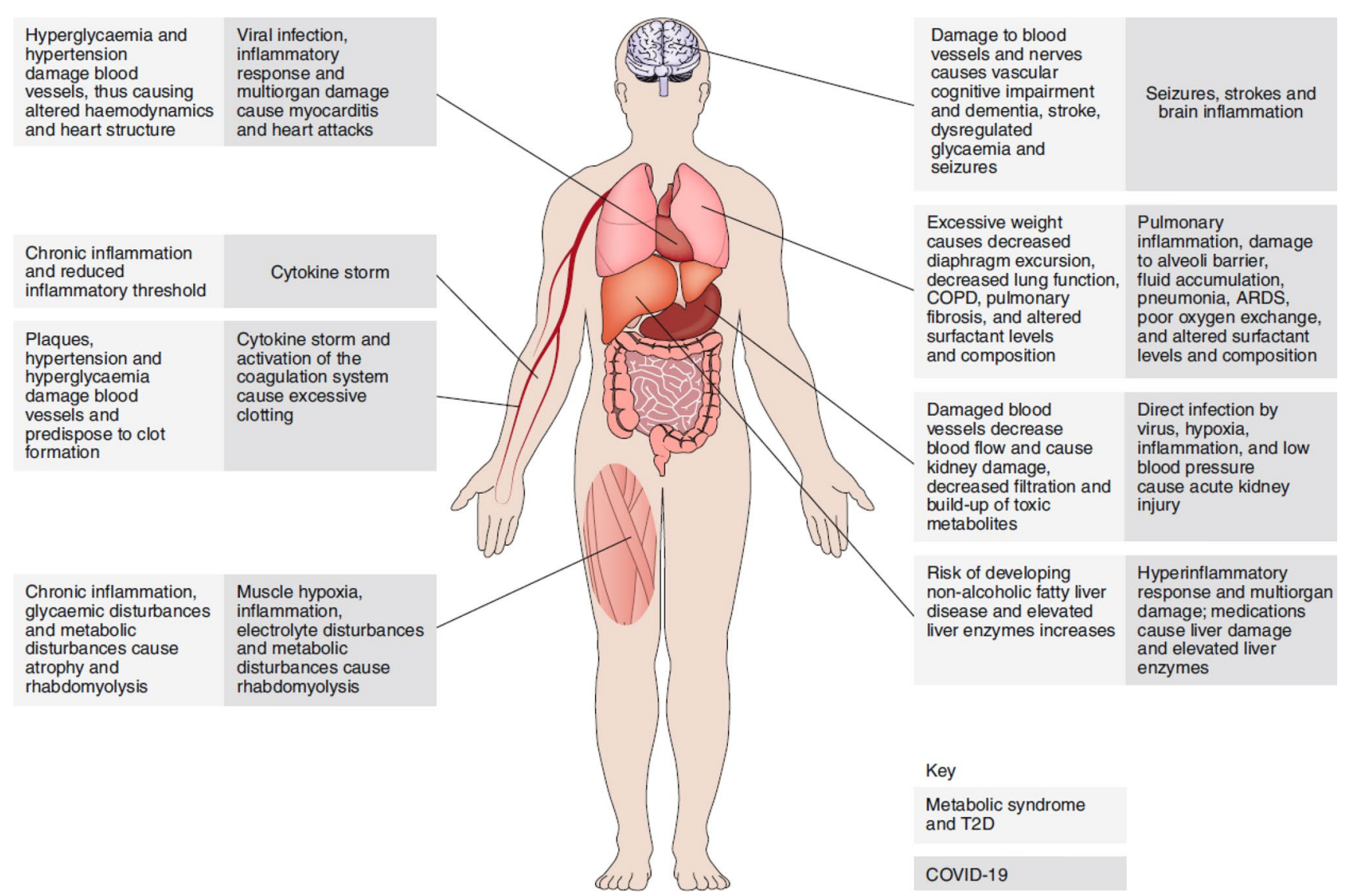

Fig. 6 The parallels among metabolic syndrome, T2D and COVID19. COVID-19, metabolic syndrome and T2D are multisystem diseases. The pathologies of metabolic syndrome and T2D affect the same systems that are damaged by COVID-19, thus predisposing patients to developing more severe pathology during the infection. We traditionally think about how metabolic syndrome and T2D make individuals more susceptible to infections because of diminished immune function, an understanding of the parallels between these conditions from a physiological perspective suggests that the greater susceptibility of these individuals to COVID-19 likely stems from an increased susceptibility to pathology and the resulting pathophysiology, rather than an inability to control the viral infection. COPD, chronic obstructive pulmonary disease, Type 2 diabetes mellitus (T2D). Adopted with permission from Ayres [43]
H1N1 decedents. Fibrin thrombi of the alveolar capillaries were identified in all cases. In two cases, there were thrombi in precapillary, capillary and post-capillary vessels. Employing a three-dimensional micro-CT of pulmonary specimens, nearly total occlusion of precapillary and postcapillary vessels were observed. The extent of endothelial cell inflammation and thrombosis was associated with structurally deformed capillaries and microvascular corrosion casting (Fig. 7). Intussusceptive angiogenesis (nonsprouting angiogenesis) occurred along with endothelial cell disruption of gap junctions and loss of contact with the basal membrane.

The extent of alveolar damage, architectural changes and vascular disruption observed in severe cases of COVID-19 are likely to cause prolonged or life-long functional abnormalities with attendant physiological limitations.

\section{Clinical follow-up strategies}

The frequency of cardiac injury, vascular dysfunction and thrombosis in patients with COVID-19, including persons with either no or minimal symptoms during their initial infection, raises important questions about potential longterm cardiovascular effects. A proactive approach to care following hospital discharge and among patients with persisting or new symptoms with a goal of prevention, education and communication is needed.

The purpose of establishing a COVID-19 Cardiovascular Clinic is to (1) proactively evaluate patients who have contracted SARS-CoV-2 infection, (2) identify cardiovascular abnormalities that could portend future serious or life-threatening events, and (3) establish a foundation for optimal management and follow-up. 

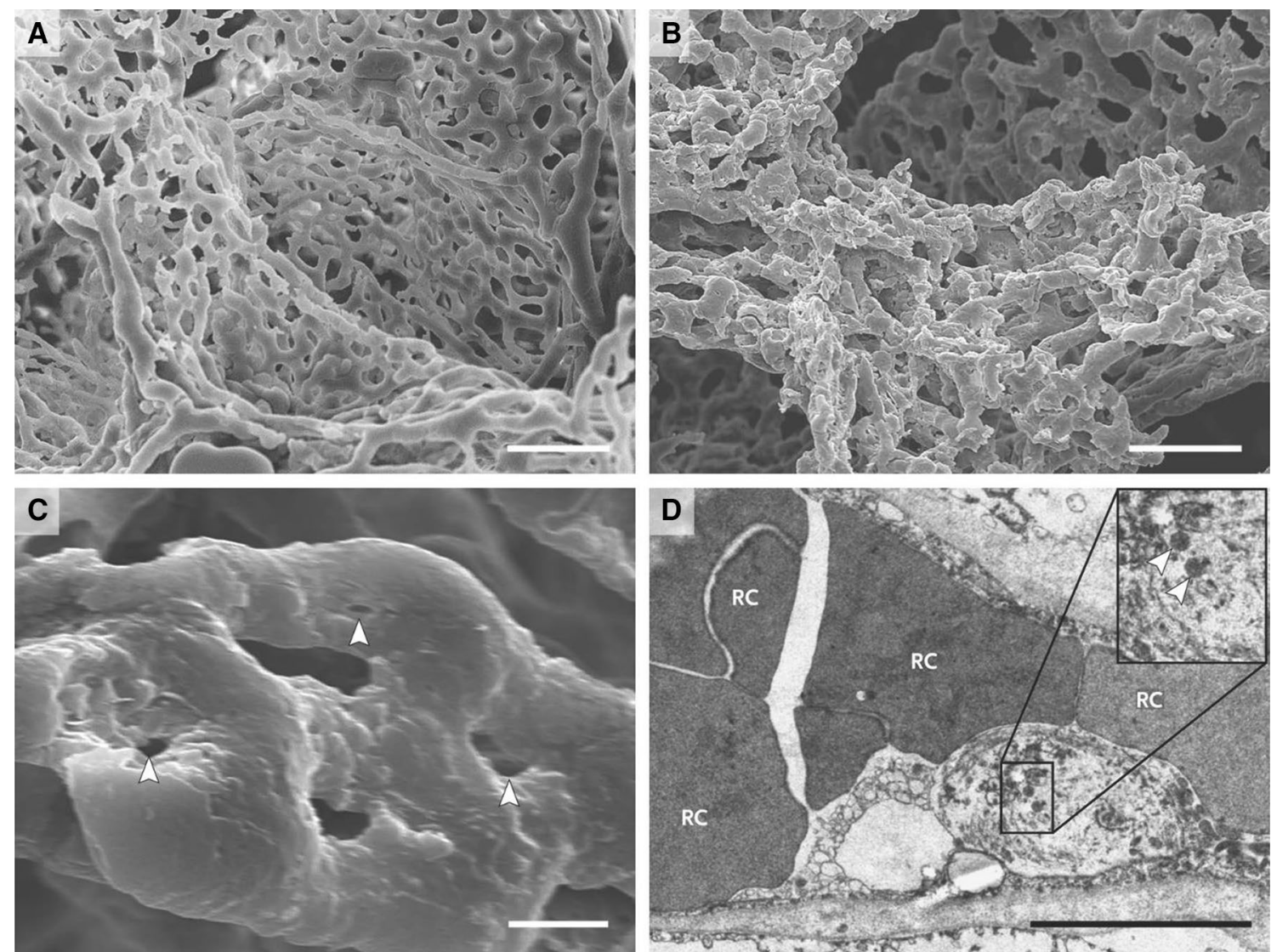

Fig. 7 a, b Scanning electron micrographs of microvascular corrosion casts from the thin-walled alveolar plexus of a healthy lung (a) and the substantial architectural distortion seen in lungs injured by Covid19 (b). The loss of a clearly visible vessel hierarchy in the alveolar plexus is the result of new blood-vessel formation by intussusceptive angiogenesis. c Shows the intussusceptive pillar localizations (arrow-

Patients with laboratory-confirmed SARS-CoV-2 infection are the focus of the clinic. Those requiring hospitalization, an intensive care unit stay and in whom there was documented cardiac injury (elevated troponin), heart failure, arrhythmias or vascular inflammation (skin or other organ biopsy) will be prioritized for evaluation. An appointment in the COVID-19 Cardiovascular Clinic could be made at the time of hospital or rehabilitation facility discharge. Persons who test positive for Covid-19 who are initially asymptomatic, but then develop shortness of breath, impaired exercise tolerance, declining stamina, persisting fatigue, presyncope or syncope should also be evaluated. Delayed-onset clinical events among SARSCoV-2 positive persons without initial symptoms, based on prior experience with viruses, will require documentation in medical records, careful history taking and reporting.

heads) at higher magnification. $\mathbf{d}$ Is a transmission electron micrograph showing ultrastructural features of endothelial cell destruction and SARS-CoV-2 visible within the cell membrane (arrowheads) (the scale bar corresponds to $5 \mu \mathrm{m})$. RC denotes red cell. Adopted with permission from Ackermann [52]

\section{Testing and diagnostic platforms}

Patients will have a complete physical examination performed by an experienced clinician. A carefully selected battery of laboratory should be considered (Table 1). A

Table 1 C19 cardiovascular clinic blood and urine tests
C-reactive protein (CRP)
D-dimer
Von Willebrand Factor (VWF): antigen and activity
Interleukin (IL)-6
Complete blood count with differential
Basic metabolic profile
Urinalysis (protein, active sediment)
Anticardiolipin antibody screen
Ferritin 
carefully selected menu of diagnostic studies to determine the status of cardiac and vascular health could also be performed as clinically indicated (Table 2). Patients would receive a COVID-19 Cardiovascular report that summarizes the findings of each recommended test, instructions for a follow-up visit or referral to a specialty clinic or treatment as indicated according to the best available evidence. An existing electronic health record or secured dedicated database should be used for documentation.

Table 2 C19 cardiovascular clinic diagnostic menu

ECG

Echocardiogram (with strain calculation)

PET-CT (option if elevated troponin during hospitalization)

Cardiac MRI (preferred for evaluation of suspected myocarditis)

$24 \mathrm{~h}$ Holter Monitor (If elevated troponin or arrhythmias during hospitalization or a left ventricular ejection fraction $\leq 40 \%$ )

Pulse wave velocity test

Brachial reactivity test

Heart rate variability test

Venous duplex scan

Pulmonary CT angiography

\section{Expertise and team-based approaches}

Establishing a COVID-19 Clinic, by the very nature of SARS-CoV-2 infection and its widespread target organ involvement, will require a collaborative and multi-disciplinary team of experts. One would anticipate a need for representation from the following specialty and subspecialty groups: cardiology (electrophysiology and heart failure), vascular medicine, pulmonary medicine, nephrology, neurology and infectious disease. Access to expertise in hematology, dermatology, psychiatry, immunology, rheumatology and social services will be a requirement as well. In addition to clinical expertise, practices, hospitals and health systems must be actively engaged to provide necessary resources, including but not limited to, radiology and other diagnostic areas, public relations, proactive dialogues with the Center for Medicare and Medicaid Services and third party payers, billing departments, electronic health records teams, champions and super-users, referral base, and community leaders to assure a clear line of communication, messaging and understanding. Clarity and transparency are the bed rocks of trust and trust is the time-honored foundation of medicine (Fig. 8).

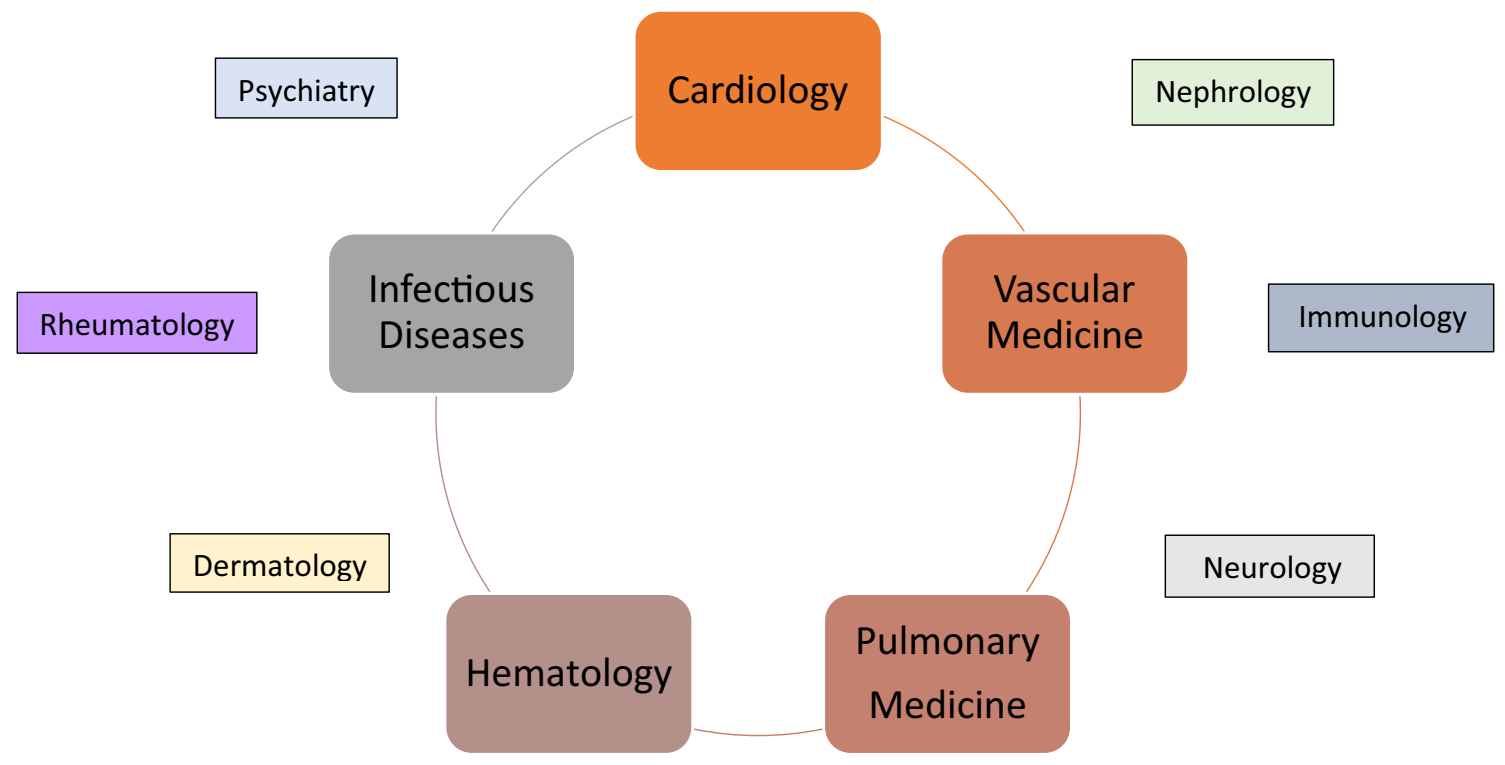

Fig. 8 COVID-19 clinics for the diagnosis and management of patients with post-COVID-19 syndrome. The approach to patients with COVID-19 either following hospital discharge or a period of illness not requiring hospitalization but with symptoms is best config- ured and operationalized in a multi-disciplinary, dedicated clinic with broad expertise, established processes, standard operating procedures, resources and identity in the medical, referral and lay communities 


\section{Research platforms}

COVID-19 clinics represent a means to render a continuum of care for patients, but they can also serve as an underpinning for research, including long-term cohort studies and research network development. The natural history of COVID-19 and the many likely forms of postCOVID-19 syndrome can only be understood by establishing initiatives for follow-up, appropriately configured databases, careful documentation with quality controls, audits, experienced staffing, over-sight and sufficient funding.

Clinical trials for COVID-19 and post-COVID-19 syndrome will require an understanding of their phenotypes, frequency and duration of risk for sample size calculations. Areas of interest and need for clinical investigation will include progressive heart failure, arrhythmias, sudden cardiac death, coagulopathy (thrombophilia), risk for venous or arterial thrombotic events and small, medium or large vessel vasculopathy with baroreceptor dysfunction, impaired autonomic responsiveness, medium-to-large vessel aneurysm formation and accelerated atherosclerosis that follows endothelial cell inflammation and injury.

Understanding the cardiovascular response to SARSCoV-2 re-infection and Influenza infection will be a particularly important area of research given the common theme in cardiovascular diseases, disorders and conditions of a "second hit phenomenon" that can accelerate pathological abnormalities and lead to clinical events. The bar must be set high to assure that research undertakings meet the vigorous standard needed to inform and advance the field [53].

\section{Concluding thoughts and future directions}

SARS-COV-2 infection is characterized by its protean nature and rapidly evolving understanding of its acute, subacute and, in all likelihood, chronic cardiovascular effects. Securing an initial diagnosis and documenting early signs, symptoms, diagnostic studies and complications, followed by an ambulatory clinic or office visit for "recovered" patients will be a vital step toward understanding COVID-19 and its comprehensive management. Research platforms must be established to translate new knowledge of post-COVID-19 syndrome to optimal patient care.

Focus on the present, but keep your eyes wide open to the future.

Richard C. Becker, MD

\section{References}

1. Carfì A, Bernabei R, Landi F (2020) Persistent symptoms in patients after acute COVID-19. JAMA 324:603-605

2. Becker RC (2020) Toward understanding the 2019 Coronavirus and its impact on the heart. J Thromb Thrombolysis. https://doi. org/10.1007/s11239-020-02107-6

3. Wichmann D, Sperhake JP, Lütgehetmann M, Steurer S, Edler C, Heinemann A, Heinrich F, Mushumba H, Kniep I, Schröder AS, Burdelski C, de Heer G, Nierhaus A, Frings D, Pfefferle S, Becker $\mathrm{H}$, Bredereke-Wiedling H, de Weerth A, Paschen HR, Sheikhzadeh-Eggers S, Stang A, Schmiedel S, Bokemeyer C, Addo MM, Aepfelbacher M, Püschel K, Kluge S (2020) Autopsy findings and venous thromboembolism in patients with COVID-19: a prospective cohort study. Ann Intern Med 173:268-277

4. Bompard F, Monnier H, Saab I, Tordjman M, Abdoul H, Fournier L, Sanchez O, Lorut C, Chassagnon G, Revel M-P (2020) Pulmonary embolism in patients with COVID-19 pneumonia. Eur Respir J 56:2001365

5. Patell R, Bogue T, Koshy AG, Bindal P, Merrill M, Aird WC, Bauer KA, Zwicker JI (2020) Post-discharge thrombosis and hemorrhage in patients with COVID-19. Blood. https://doi. org/10.1182/blood.2020007938

6. Patell R, Bogue T, Bindal P, Koshy A, Merrill M, Aird WC, Bauer KA, Zwicker JI (2020) Incidence of thrombosis and hemorrhage in hospitalized cancer patients with COVID-19. J Thromb Haemost. https://doi.org/10.1111/jth.15018

7. Paulino M, Dumas-Diniz R, Brissos S, Brites R, Alho L, Simões MR, Silva CF (2020) COVID-19 in Portugal: exploring the immediate psychological impact on the general population. Psychol Health Med. https://doi.org/10.1080/13548506.2020.1808236

8. Ebinger JE, Achamallah N, Ji H, Claggett BL, Sun N, Botting P, Nguyen TT, Luong E, Kim EH, Park E, Liu Y, Rosenberry R, Matusov Y, Zhao S, Pedraza I, Zaman T, Thompson M, Raedschelders K, Berg AH, Grein JD, Noble PW, Chugh SS, Bairey Merz CN, Marbán E, Van Eyk JE, Solomon SD, Albert CM, Chen P, Cheng S (2020) Pre-existing traits associated with Covid-19 illness severity. PLoS ONE 15:e0236240

9. Razzaghi H, Wang Y, Lu H, Marshall KE, Dowling NF, PazBailey G, Twentyman ER, Peacock G, Greenlund KJ (2020) Estimated county-level prevalence of selected underlying medical conditions associated with increased risk for severe COVID19 illness-United States, 2018. MMWR Morb Mortal Wkly Rep 69:945-950

10. DeFilippis AP, Chapman AR, Mills NL, de Lemos JA, ArbabZadeh A, Newby LK, Morrow DA (2019) Assessment and treatment of patients with Type 2 myocardial infarction and acute nonischemic myocardial injury. Circulation 140:1661-1678

11. Becker RC (2020) COVID-19 update: Covid-19-associated coagulopathy. J Thromb Thrombolysis 50:54-67

12. Jain SS, Liu Q, Raikhelkar J, Fried J, Elias P, Poterucha TJ, DeFilippis EM, Rosenblum H, Wang EY, Redfors B, Clerkin K, Griffin JM, Wan EY, Abdalla M, Bello NA, Hahn RT, Shimbo D, Weiner SD, Kirtane AJ, Kodali SK, Burkhoff D, Rabbani LE, Schwartz A, Leon MB, Homma S, Di Tullio MR, Sayer G, Uriel $\mathrm{N}$, Anstey DE (2020) Indications for and findings on transthoracic echocardiography in COVID-19. J Am Soc Echocardiogr. https:// doi.org/10.1016/j.echo.2020.06.009

13. Mall G, Klingel K, Albrecht M, Seemann M, Rieger P, Kandolf R (1991) Natural history of coxsackievirus B3-induced myocarditis in ACA/Sn mice: viral persistence demonstrated by quantitative in situ hybridization histochemistry. Eur Heart J 12:121-123

14. Pollack A, Kontorovich AR, Fuster V, Dec GW (2015) Viral myocarditis-diagnosis, treatment options, and current controversies. Nat Rev Cardiol 12:670-680 
15. Bültmann BD, Sotlar K, Klingel K (2004) Parvovirus B19. N Engl J Med 350:2006-2007

16. Lasrado N, Yalaka B, Reddy J (2020) Triggers of inflammatory heart disease. Front Cell Dev Biol 8:192

17. Fujinami RS, von Herrath MG, Christen U, Whitton JL (2006) Molecular mimicry, bystander activation, or viral persistence: infections and autoimmune disease. Clin Microbiol Rev 19:80-94

18. Lindner D, Fitzek A, Bräuninger H, Aleshcheva G, Edler C, Meissner K, Scherschel K, Kirchhof P, Escher F, Schultheiss H-P, Blankenberg S, Püschel K, Westermann D (2020) Association of cardiac infection with SARS-CoV-2 in confirmed COVID-19 autopsy cases. JAMA Cardiol. https://doi.org/10.1001/jamacardio .2020 .3551

19. Puntmann VO, Carerj ML, Wieters I, Fahim M, Arendt C, Hoffmann J, Shchendrygina A, Escher F, Vasa-Nicotera M, Zeiher AM, Vehreschild M, Nagel E (2020) Outcomes of cardiovascular magnetic resonance imaging in patients recently recovered from coronavirus disease 2019 (COVID-19). JAMA Cardiol. https:// doi.org/10.1001/jamacardio.2020.3557

20. Herskowitz A, Campbell S, Deckers J, Kasper EK, Boehmer J, Hadian D, Neumann DA, Baughman KL (1993) Demographic features and prevalence of idiopathic myocarditis in patients undergoing endomyocardial biopsy. Am J Cardiol 71:982-986

21. Maron BJ, Udelson JE, Bonow RO, Nishimura RA, Ackerman MJ, Estes NA 3rd, Cooper LT Jr, Link MS, Maron MS (2015) Eligibility and disqualification recommendations for competitive athletes with cardiovascular abnormalities: task force 3-hypertrophic cardiomyopathy, arrhythmogenic right ventricular cardiomyopathy and other cardiomyopathies, and myocarditis-a scientific statement from the American heart association and American college of cardiology. Circulation 132:e273-e280

22. Phelan D, Kim JH, Chung EH (2020) A game plan for the resumption of sport and exercise after coronavirus disease 2019 (COVID19) infection. JAMA Cardiol. https://doi.org/10.1001/jamacardio .2020 .2136

23. Su H, Yang M, Wan C, Yi LX, Tang F, Zhu HY, Yi F, Yang HC, Fogo AB, Nie X, Zhang C (2020) Renal histopathological analysis of 26 postmortem findings of patients with COVID-19 in China. Kidney Int 98:219-227

24. Peleg Y, Kudose S, D’Agati V, Siddall E, Ahmad S, Kisselev S, Gharavi A, Canetta P (2020) Acute kidney injury due to collapsing glomerulopathy following COVID-19 infection. Kidney Int Rep 5:940-945

25. Farouk SS, Fiaccadori E, Cravedi P, Campbell KN (2020) COVID-19 and the kidney: what we think we know so far and what we don't. J Nephrol. https://doi.org/10.1007/s40620-02000789-y

26. Yap SC, Lee HT (2012) Acute kidney injury and extrarenal organ dysfunction: new concepts and experimental evidence. Anesthesiology 116:1139-1148

27. Vergaro G, Prud'homme M, Fazal L, Merval R, Passino C, Emdin M, Samuel J-L, Solal AC and Delcayre C. (2016) Inhibition of galectin-3 pathway prevents isoproterenol-induced left ventricular dysfunction and fibrosis in mice. Hypertension 67:606-612

28. Di Lullo L, Reeves PB, Bellasi A, Ronco C (2019) Cardiorenal syndrome in acute kidney injury. Semin Nephrol 39:31-40

29. Chen B, Frangogiannis NG (2020) Chemokines in myocardial infarction. J cardiovasc Transl Res. https://doi.org/10.1007/s1226 5-020-10006-7

30. Ronco C, Haapio M, House AA, Anavekar N, Bellomo R (2008) Cardiorenal syndrome. J Am Coll Cardiol 52:1527-1539

31. Ikizler TA, Parikh CR, Himmelfarb J, Chinchilli VM, Liu KD, Coca SG, Garg AX, Hsu CY, Siew ED, Wurfel MM, Ware LB, Faulkner GB, Tan TC, Kaufman JS, Kimmel PL, Go AS (2020) A prospective cohort study that examined acute kidney injury and kidney outcomes, cardiovascular events and death informs on long-term clinical outcomes. Kidney Int. https://doi. org/10.1016/j.kint.2020.06.032

32. Varga Z, Flammer AJ, Steiger P, Haberecker M, Andermatt R, Zinkernagel AS, Mehra MR, Schuepbach RA, Ruschitzka F, Moch H (2020) Endothelial cell infection and endotheliitis in COVID-19. Lancet. https://doi.org/10.1016/S0140 $-6736(20) 30937-5$

33. Sharma A, Garcia G, Arumugaswami V, Svendsen CN (2020) Human iPSC-derived cardiomyocytes are susceptible to SARSCoV-2 infection. Cell Rep Med. https://doi.org/10.1016/j. xcrm.2020.100052

34. Chatterjee V, Yang X, Ma Y, Cha B, Meegan JE, Wu M, Yuan SY (2019) Endothelial microvesicles carrying Src-rich cargo impair adherens junction integrity and cytoskeleton homeostasis. Cardiovasc Res. https://doi.org/10.1093/cvr/cvz238

35. Robles-Cabrera A, Michel-Chávez A, Callejas-Rojas RC, Malamud-Kessler C, Delgado G, Estañol-Vidal B (2014) The cardiovagal, cardiosympathetic and vasosympathetic arterial baroreflexes and the neural control of short-term blood pressure. Revista de Neurologia. 59:508-516

36. Kirchheim HR (1976) Systemic arterial baroreceptor reflexes. Physiol Rev 56:100-177

37. Pennisi M, Lanza G, Falzone L, Fisicaro F, Ferri R, Bella R (2020) SARS-CoV-2 and the nervous system: from clinical features to molecular mechanisms. Int J Mol Sci. https://doi.org/10.3390/ ijms 21155475

38. Ayres JS (2020) Surviving COVID-19: a disease tolerance perspective. Sci Adv. https://doi.org/10.1126/sciadv.abc1518

39. Braun J, Loyal L, Frentsch M, Wendisch D, Georg P, Kurth F, Hippenstiel S, Dingeldey M, Kruse B, Fauchere F, Baysal E, Mangold M, Henze L, Lauster R, Mall MA, Beyer K, Röhmel J, Voigt S, Schmitz J, Miltenyi S, Demuth I, Müller MA, Hocke A, Witzenrath M, Suttorp N, Kern F, Reimer U, Wenschuh H, Drosten C, Corman VM, Giesecke-Thiel C, Sander LE, Thiel A (2020) SARS-CoV-2-reactive T cells in healthy donors and patients with COVID-19. Nature. https://doi.org/10.1038/s41586-020-2598-9

40. Yang L, Liu S, Liu J, Zhang Z, Wan X, Huang B, Chen Y, Zhang Y (2020) COVID-19: immunopathogenesis and immunotherapeutics. Sig Transduct Target Ther 5:128

41. Wen W, Su W, Tang H, Le W, Zhang X, Zheng Y, Liu X, Xie L, Li J, Ye J, Dong L, Cui X, Miao Y, Wang D, Dong J, Xiao C, Chen W, Wang H (2020) Immune cell profiling of COVID-19 patients in the recovery stageby single-cell sequencing. Cell Discov 6:31

42. Chua RL, Lukassen S, Trump S, Hennig BP, Wendisch D, Pott F, Debnath O, Thürmann L, Kurth F, Völker MT, Kazmierski J, Timmermann B, Twardziok S, Schneider S, Machleidt F, Müller-Redetzky H, Maier M, Krannich A, Schmidt S, Balzer F, Liebig J, Loske J, Suttorp N, Eils J, Ishaque N, Liebert UG, von Kalle C, Hocke A, Witzenrath M, Goffinet C, Drosten C, Laudi S, Lehmann I, Conrad C, Sander L-E, Eils R (2020) COVID-19 severity correlates with airway epithelium-immune cell interactions identified by single-cell analysis. Nat Biotechnol 38:970-979

43. Ayres JS (2020) A metabolic handbook for the COVID-19 pandemic. Nat Metab 2:572-585

44. Kass DA, Duggal P, Cingolani O (2020) Obesity could shift severe COVID-19 disease to younger ages. Lancet 395:1544-1545

45. Ali M, Girgis S, Hassan A, Rudick S, Becker RC (2018) Inflammation and coronary artery disease: from pathophysiology to Canakinumab Anti-Inflammatory Thrombosis Outcomes Study (CANTOS). Coron Artery Dis 29:429-437

46. D'Marco L, Puchades MJ, Romero-Parra M, Gimenez-Civera E, Soler MJ, Ortiz A, Gorriz JL (2020) Coronavirus disease 2019 in chronic kidney disease. Clin Kidney J 13:297-306

47. Yang J, Brody EN, Murthy AC, Mehler RE, Weiss SJ, DeLisle RK, Ostroff R, Williams SA, Ganz P (2020) Impact of kidney function on the blood proteome and on protein cardiovascular risk 
biomarkers in patients with stable coronary heart disease. J Am Heart Assoc 9:e016463

48. Wang CH, Liu CY, Wan YL, Chou CL, Huang KH, Lin HC, Lin SM, Lin TY, Chung KF, Kuo HP (2005) Persistence of lung inflammation and lung cytokines with high-resolution CT abnormalities during recovery from SARS. Respir Res 6:42

49. Wu Z, McGoogan JM (2020) Characteristics of and important lessons from the coronavirus disease 2019 (COVID-19) outbreak in China: summary of a report of 72314 cases from the Chinese center for disease control and prevention. JAMA. https://doi. org/10.1001/jama.2020.2648

50. Sasannejad C, Ely EW, Lahiri S (2019) Long-term cognitive impairment after acute respiratory distress syndrome: a review of clinical impact and pathophysiological mechanisms. Crit Care $23: 352$

51. Song JW, Lam SM, Fan X, Cao WJ, Wang SY, Tian H, Chua GH, Zhang C, Meng FP, Xu Z, Fu JL, Huang L, Xia P, Yang T, Zhang S, Li B, Jiang TJ, Wang R, Wang Z, Shi M, Zhang JY, Wang FS, Shui G (2020) Omics-driven systems interrogation of metabolic dysregulation in COVID-19 pathogenesis. Cell Metab 32(188-202):e5
52. Ackermann M, Verleden SE, Kuehnel M, Haverich A, Welte T, Laenger F, Vanstapel A, Werlein C, Stark H, Tzankov A, Li WW, Li VW, Mentzer SJ, Jonigk D (2020) Pulmonary vascular endothelialitis, thrombosis, and angiogenesis in Covid-19. N Eng1 J Med. https://doi.org/10.1056/NEJMoa2015432

53. Pundi K, Perino AC, Harrington RA, Krumholz HM, Turakhia MP (2020) Characteristics and strength of evidence of COVID-19 studies registered on ClinicalTrials.gov. JAMA Internl Med. https ://doi.org/10.1001/jamainternmed.2020.2904

54. Ebinger JE (2020) Estimated County-Level Prevalence of Selected Underlying Medical Conditions Associated with Increased Risk for Severe COVID-19 Illness-United States, 2018. MMWR Morb Mortal Wkly Rep. 69:945-950

Publisher's Note Springer Nature remains neutral with regard to jurisdictional claims in published maps and institutional affiliations. 